\title{
Volume-effecten van enkele WAO-voorstellen
}

\author{
J.J.M. Besseling
}

Samenvatting In dit artikel wordt van drie voorgenomen WAO-maatregelen het verwachte volume-effect op de WAO-instroom gepresenteerd. De analyses zijn uitgevoerd voor een emancipatie-effectrapportage op de plannen van de commissie-Donner. Gebruik is gemaakt van statistische gegevens van het Lisv over 1999 en 2000. Invoering van een arbeidsverledeneis zoals in de WW, leidt tot $17 \%$ minder WAO-toekenningen. Het effect is voor vrouwen iets groter dan voor mannen. Afschaffing van de lagere arbeidsongeschiktheidsklassen heeft, ongeacht welke ondergrens wordt gekozen, voor mannen een groter effect dan voor vrouwen. Als de ondergrens op $80 \%$ wordt gesteld, en dus de gedeeltelijke WAO-uitkering wordt afgeschaft, zou de instroomreductie in 2000 $38 \%$ zijn geweest. Als alleen 'echte' volledig arbeidsongeschikten in aanmerking kunnen komen voor de WAO, zal het effect voor vrouwen kleiner zijn dan voor mannen. Bij mannen daalt de instroom in de WAO met $73 \%$ en bij vrouwen met $67 \%$. De raming voor de emancipatie-effectrapportage wordt vergeleken met de raming door de commissie-Donner.

Keywords WAO-maatregelen • volume-effecten . referte-eis · commissie-Donner · emancipatieeffectrapportage

\section{Inleiding}

Het terugdringen van (langdurig) ziekteverzuim en de instroom in de WAO staat al een flink aantal jaren hoog op de politieke agenda. Het grote aantal arbeidsongeschikten in Nederland wordt in brede kring als probleem gezien. Over de noodzaak werk te maken van arbeidsongeschiktheid bestaat in grote lijnen consensus. De mogelijke beleidsvoorstellen en ballonnetjes zijn legio. De commissie-Donner, ${ }^{1}$ de SER, kabinet-Kok, kabinet-Balkenende I en II, de VVD, eenieder geeft op net weer andere wijze invulling aan de gedachte dat de instroom in de WAO beheerst kan worden door de toelatingscriteria te wijzigen zoals:

1. verhoging van de ondergrens tot $50 \%$, tot tweederde of het volledig afschaffen van de gedeeltelijke WAOuitkering;

2. introduceren van een arbeidsverledeneis zodat recht op een WAO-uitkering pas na een afgebakende periode ontstaat;

3. een strenger WAO-criterium zodat bijvoorbeeld alleen duurzame, onomkeerbare niet vermijdbare arbeidsongeschikten in de WAO kunnen komen;

4. het uitsluiten van psychisch zieken voor een WAOuitkering;

5. het uitsluiten van bepaalde sociale risico's c.q. riskante leefgewoonten als reden voor een WAO-uitkering;

6. het verlengen van de wachttijd voor de WAO van één naar twee jaar.

In dit artikel wordt van de eerste drie mogelijke maatregelen aangegeven welke kwantitatieve effecten verwacht mogen worden op de WAO-instroom. Dat gebeurt door de maatregelen met 'terugwerkende kracht' 
Tabel 1 Instroomreductie door toepassing arbeidsverledeneis op een steekproef van cohort 1999, twee varianten.

\begin{tabular}{lrrr}
\hline & Man $^{\mathrm{a}}$ & Vrouw $^{\mathrm{b}}$ & Totaal \\
\hline 2-uit-3 jaren eis & $8 \%$ & $8 \%$ & $8 \%$ \\
4-uit-5 jaren eis & $15 \%$ & $18 \%$ & $17 \%$ \\
aantal in steekproef & 4234 & 5246 & 9480
\end{tabular}

Bron: eigen berekening op basis van Lisv-gegevens. ${ }^{2}$

a: onbekend $2 \%$.

b: onbekend $1 \%$.

toe te passen op de WAO-instroom in 1999 of 2000 . Het betreft de kwantitatieve effecten van:

1. invoering van een arbeidsverledeneis;

2. verhoging van de toelatingsdrempel c.q. laagste arbeidsongeschiktheidsklasse;

3. strenger arbeidsongeschiktheidscriterium.

Deze maatregelen zijn genoemd in het regeerakkoord en dus zeer actueel.

De analyses zijn uitgevoerd in het kader van een zogeheten emancipatie-effectrapportage (EER) ${ }^{2}$ naar aanleiding van het rapport van de commissie-Donner. De effecten worden dan ook voor mannen en vrouwen weergegeven en besproken. Zijdelings wordt ingegaan op de vraag welke subgroepen (leeftijd, diagnose en sector) meer, dan wel minder, dan evenredig worden getroffen. Getroffen wil zeggen dat men onder het huidige WAObeleid een WAO-uitkering ontvangt of zou ontvangen en bij identieke omstandigheden door het nieuwe beleid niet meer in aanmerking komt voor een WAO-uitkering.

De kwantitatieve effecten zijn berekend op bestanden met statistische gegevens van het Lisv over 1999 en 2000. De effecten van een arbeidsverledeneis en een hogere drempel konden zonder nadere aannames direct op de statistische gegevens worden berekend. Om het effect van een strenger ao-criterium te kunnen vaststellen was het nodig om daartoe een eigen operationalisatie te ontwikkelen van het strengere ao-criterium. De wijze waarop het begrip is ingevuld wordt vergeleken met hetgeen Donner beoogde.

Bij de uitvoering van de analyses kon geen rekening worden gehouden met zogeheten 'gedragseffecten' naar aanleiding van de beleidsvoornemens. Tevens is geen rekening gehouden met de beleidsoptie om de wachttijd voor de WAO te verlengen van één naar twee jaar aangezien die optie op dat moment niet bekend was.

1. Als alleen duurzaam, niet-vermijdbaar, volledig arbeidsongeschikten toegelaten worden tot de WAO treft dat meer mannen dan vrouwen.

2. Het effect van zo'n nieuw criterium zou kunnen oplopen tot $70 \%$ minder nieuwe WAO'ers.
3. Onbekend is nog of én hoe dit nieuwe criterium uitgevoerd kan worden

\section{Arbeidsverledeneis}

Invoering van een referte-eis maakte geen deel uit van de voorstellen van de commissie-Donner. De commissie bespreekt de referteeis wel als één van de voorstellen die de afgelopen jaren zijn gedaan om het beroep op de WAO terug te dringen. Het is een stokpaardje van de VVD. ${ }^{3}$ Het stellen van een referte-eis is dan ook onderdeel van het huidige regeerakkoord geworden. In de WW wordt een arbeidsverledeneis gehanteerd als voorwaarde voor het ontstaan van het recht op WW. Vanuit emancipatieperspectief is destijds het zogeheten verzorgingsforfait ingesteld dat, evenals het opnemen van onbetaald verlof ten behoeve van zorgtaken, onder voorwaarden gelijkgesteld wordt met het voldaan hebben aan loondagen voor de arbeidsverledeneis. ${ }^{4}$

Voor een $10 \%$ steekproef van het instroomcohort 1999 aan wie een WAO-uitkering is toegekend, heeft het Lisv het arbeidsverleden onderzocht en op basis van bestandsgegevens vastgesteld in hoeverre men voldoet aan twee basisvarianten van een arbeidsverledeneis:

1. arbeidsverleden in minimaal 4 van de 5 laatste jaren (overeenkomstig eisen in de WW);

2. arbeidsverleden in minimaal 2 van de 3 laatste jaren.

De bestanden van het Lisv bevatten geen informatie waarmee de effecten van toepassing van een verzorgingsforfait of onbetaald zorgverlof onderzocht kunnen worden.

Toepassing van de 2 uit 3 arbeidsverledeneis zou tot gevolg hebben dat aan $8 \%$ van de personen in cohort 1999 geen WAO toegekend zou worden omdat volgens de bestandsgegevens van het Lisv niet in minstens 2 van de 3 jaren voldoende loondagen zijn geweest. Bij toepassing van een 4 uit 5 arbeidsverledeneis zou aan $17 \%$ van de personen geen WAO-uitkering toegekend worden. Slechts voor een klein percentage personen ontbrak de informatie om de simulatie uit te kunnen voeren. Uit tabel 1 blijkt dat het relatieve effect van een 2 uit 3 arbeidsverledeneis voor mannen en vrouwen gelijk is.

Toepassing van een 4 uit 5 jareneis heeft voor vrouwen een iets groter effect dan voor mannen. Van de vrouwen zou $18 \%$ niet voldoen tegenover $15 \%$ van de mannen.

Analyse op achtergrondkenmerken leert dat, zoals te verwachten was, jongeren meer worden getroffen dan ouderen. Opvallend is daarbij dat in de leeftijdsgroepen onder 35 jaar mannen meer worden getroffen dan vrouwen en boven de 35 jaar worden vrouwen iets meer getroffen dan mannen. Ook plausibel is dat WAO'ers 
met hoofddiagnose 'letsel' iets vaker niet aan een arbeidsverledeneis voldoen, omdat letsels vaker bij jongeren voorkomen. De helft van de WAO'ers in de uitzendbranche voldoet niet aan een 4 uit 5 arbeidsverledeneis. Dat percentage is voor mannen en vrouwen vrijwel gelijk. Relatief veel vrouwelijke WAO'ers bij het GUO voldoen niet aan een arbeidsverledeneis: $31 \%$ voldoet niet aan een 4 uit 5 eis. WAO'ers bij het USZO hebben weinig te vrezen van een referte-eis. Slechts $4 \%$ van de mannelijke WAO'ers en 6\% van de vrouwelijke WAO'ers bij het USZO voldoet niet aan een 4 uit 5 eis.

\section{Afschaffing lagere ao-klassen}

De mate van arbeidsongeschiktheid wordt in de huidige WAO uitgedrukt in 8 klassen lopend van minder dan $15 \%$ (niet arbeidsongeschikt in de zin van WAO), tot 80 tot $100 \%$ ('volledig arbeidsongeschikt'). In de discussie zijn diverse voorstellen gedaan om de ondergrens voor de WAO te verhogen. In dit artikel worden vier varianten gepresenteerd.

In de eerste variant wordt de ondergrens voor alle drie arbeidsongeschiktheidswetten (WAO, WAZ en Wajong) gelijk getrokken $(<25 \%$ ao). De tweede variant sluit aan bij het SER-voorstel om de ondergrens voor arbeidsongeschiktheid bij 35\% te leggen. De derde variant sluit aan bij de optie dat degenen die voor minder dan de helft arbeidsongeschikt zijn, niet meer tot de doelgroep voor deze arbeidsongeschiktheidswetten behoren. Op basis van de beschikbare statische gegevens kan de grens niet exact bij $50 \%$ gelegd worden maar is gekozen voor de aoklasse $(45-55 \%$ ao) waarvan het klassemidden $50 \%$ bedraagt. De vierde variant sluit aan bij de plannen van Donner en van het huidige kabinet waarin wordt voorgesteld de WAO te reserveren voor volledig arbeidsongeschikten. De berekeningen zijn uitgevoerd op gegevens van het Lisv van nieuwe WAO-uitkeringen in 2000.

2 vermeldt het volume-effect van de vier varianten op de jaarlijkse instroom. Voor elke variant wordt aangegeven hoeveel procent niet meer in aanmerking zou komen voor een (gedeeltelijke) WAO-uitkering, met andere woorden met hoeveel procent de WAO-instroom zou dalen.

Als in 2000 een drempel van $25 \%$ geïntroduceerd zou zijn, zouden $9 \%$ van de mannen geen WAO-uitkering meer ontvangen en $7 \%$ van de vrouwen, totaal $8 \%$. Deze percentages lopen uiteraard op als de toetredingsdrempel hoger komt te liggen. Als de ondergrens bij 80\% wordt gelegd waarbij gedeeltelijke arbeidsongeschiktheid geen recht meer geeft op een arbeidsongeschiktheidsuitkering zouden $45 \%$ van de mannen geen WAO-uitkering meer ontvangen en $33 \%$ van de vrouwen. Voor alle varianten geldt dat de instroomreductie bij mannen groter is dan bij vrouwen. Vrouwen zouden door deze maatregel in mindere mate worden getroffen dan mannen.

Analyse naar achtergrondkenmerken geeft aan dat de effecten het sterkst zijn voor WAO'ers van middelbare leeftijd. Beperken we ons tot de strengste variant waarbij alleen volledig arbeidsongeschikten recht hebben op een WAO-uitkering dan worden de jongste WAO-vrouwen (onder de 20 jaar) het minst getroffen $(12 \%)$ en de mannelijke WAO'ers van 45 tot 54 jaar het zwaarst (51\%). Van de vrouwelijke WAO'ers in die leeftijdsklasse wordt $36 \%$ getroffen. Vooral de WAO'ers bij het USZO worden zwaar getroffen: $60 \%$ van de mannelijke WAO'ers en $52 \%$ van de vrouwelijke WAO'ers bij het USZO zou worden getroffen door deze maatregel. WAO'ers in hoofddiagnosecategorie 'bewegingsstelsel' worden meer dan gemiddeld getroffen (mannen $58 \%$, vrouwen $38 \%$ ) en WAO'ers met een 'psychische stoornis' minder dan gemiddeld (resp. $37 \%$ en $31 \%$ ).

\section{Strenger arbeidsongeschiktheidscriterium}

Het huidige kabinet opteert ervoor, in navolging van de plannen van de commissie-Donner, om de WAOinstroom te beperken door de WAO te reserveren voor echte volledig arbeidsongeschikten. Daartoe stelde de commissie voor het arbeidsongeschiktheidscriterium aan te passen. Het begrip arbeidsongeschiktheid kent twee fundamentele wijzigingen vergeleken met de huidige situatie:

1. de commissie gaat uit van arbeidscapaciteit in plaats van verdiencapaciteit en verlaat daarmee de essentie van de huidige verzekering, waarbij het object van verzekering loonderving door ziekte is;

2. de commissie kent alleen nog volledige en duurzame arbeidsongeschiktheid die bovendien onvermijdbaar dient te zijn.

Hoewel nog niet duidelijk is welke invulling van het nieuwe criterium de commissie voor ogen heeft (gehad), is wel duidelijk dat zeer strikte hantering van het criterium vergaande effecten zal hebben. Allereerst zullen allen die onder het huidige criterium gedeeltelijk arbeidsongeschikt zijn, per definitie niet meer in aanmerking komen voor de WAO omdat bij deze groep resterende verdiencapaciteit en dus arbeidscapaciteit is vastgesteld. Echter ook een deel van de huidige volledig arbeidsongeschikten zal volgens het nieuwe criterium niet meer in aanmerking komen voor de WAO. Dat zijn bijvoorbeeld degenen bij wie wel arbeidscapaciteit aanwezig is maar geen verdiencapaciteit volgens de huidige CBBS-systematiek. Of de arbeidsongeschiktheid is niet duurzaam 
Tabel 2 Reductie in nieuwe WAO-uitkeringen (2000) door verhoging van de toetredingsdrempel, vier varianten, naar geslacht.

\begin{tabular}{lrrr}
\hline & \multicolumn{3}{c}{ Instroomreductie } \\
\hline Ondergrens & mannen & vrouwen & totaal \\
\hline$<25 \%$ ao & $9 \%$ & $7 \%$ & $15 \%$ \\
$<35 \%$ ao & $20 \%$ & $15 \%$ & $21 \%$ \\
$<45 \%$ ao & $28 \%$ & $24 \%$ \\
$<80 \%$ ao & $45 \%$ & $33 \%$ & $38 \%$ \\
\hline
\end{tabular}

Bron: eigen berekening op basis van Lisv-gegevens. ${ }^{2}$

Tabel 3 Effect van de invulling van een nieuw ao-criterium op de WAO-instroom volgens de emancipatie-effectrapportage (EER) en de commissie-Donner (cumulatieve effecten).

\begin{tabular}{|c|c|c|c|c|c|c|}
\hline \multirow{3}{*}{\multicolumn{2}{|c|}{ Stappen in Donner }} & \multicolumn{3}{|c|}{ WAO-instroomreductie } & \multicolumn{2}{|l|}{ Stappen in EER } \\
\hline & & Donner* & & $\mathrm{EER}^{* *}$ & & \\
\hline & & totaal & $\operatorname{man}$ & vrouw & & \\
\hline 1 & afschaffing laagste ao-klasse & $37 \%$ & $45 \%$ & $33 \%$ & afschaffing laagste ao-klasse & 1 \\
\hline 2 & $\begin{array}{r}\text { herstelde volledig ao'en binnen één jaar } \\
\text { niet in WAO }\end{array}$ & $45 \%$ & & & & \\
\hline \multirow[t]{2}{*}{3} & alleen GDBM in WAO & $55 \%$ & $63 \%$ & $54 \%$ & indien FIS geraadpleegd, geen WAO & 2 \\
\hline & & & $71 \%$ & $65 \%$ & $\begin{array}{r}\text { helft van de psychisch zieken is niet duurzaam en } \\
\text { vermijdbaar ao }\end{array}$ & 3 \\
\hline 4 & strengste invulling & $67 \%$ & $73 \%$ & $67 \%$ & $\begin{array}{r}10 \% \text { van de 'niet-psychisch zieken' is niet duurzaam en } \\
\text { niet vermijdbaar ao }\end{array}$ & 4 \\
\hline
\end{tabular}

en niet onvermijdbaar. Veelal denkt men daarbij als eerste aan de psychisch zieken. Zo is door het CPB een voorstel doorgerekend om het arbeidsongeschiktheidscriterium zo te wijzigen dat alleen recht op een (volledige) WAO-uitkering kan ontstaan indien psychische klachten het persoonlijk en sociaal functioneren onmogelijk maken dan wel in geval van opname in een ziekenhuis of instelling voor ten minste drie maanden. In die berekeningen gaat het CPB ervan uit dat ongeveer de helft van de psychisch zieken geen recht meer zou hebben op een WAO-uitkering. ${ }^{5}$

Bij de analyse voor de emancipatie-effect rapportage (EER) is in vier volgtijdelijke stappen een berekening gemaakt die zoveel mogelijk aansluit bij de definitie van Donner:

1. 'Volledig arbeidsongeschikt' is benaderd door uit te gaan van een toelatingsdrempel van $80 \%$ arbeidsongeschiktheid.

2. 'Het beschikken over arbeidscapaciteit' is uitgesloten door iedereen waarvoor het Functie Informatie Systeem (FIS), de voorganger van het huidige CBBS, is geraadpleegd geen WAO-uitkering meer toe te kennen.

'Duurzaam en vermijdbaar' is ingevuld door een deel van de huidige volledig arbeidsongeschikten waarvoor het FIS niet is geraadpleegd te bestempelen als vermijdbaar en niet duurzaam arbeidsongeschikt. De veronderstelling is dat de gevolgen groot zullen zijn voor de 'psychisch zieken' en marginaal zullen zijn voor de 'overigen':

1. Van de helft van de huidige volledige arbeidsongeschikten met een diagnose 'psychisch' wordt de arbeidsongeschiktheid, in navolging van het CPB, bestempeld als niet duurzaam en/of vermijdbaar.

2. En van de overige volledig arbeidsongeschikten wordt slechts $10 \%$ bestempeld als niet duurzaam en/of vermijdbaar arbeidsongeschikt.

Ook de effecten van de plannen van Donner zijn in vier stappen geraamd al worden die in het rapport aangeduid als basisscenario's. In tabel 3 worden de effecten volgens beide ramingen in vier stappen weergegeven. De commissie-Donner maakt bij het ramen van de effecten geen onderscheid naar geslacht.

De eerste stap is ook bij de commissie-Donner de afschaffing van de gedeeltelijke arbeidsongeschiktheid. Dit leidt tot een WAO-instroomreductie van 37\%. De tweede stap is dat volledig arbeidsongeschikten die binnen één jaar herstellen in dienst van hun werkgever blijven en niet in de WAO komen. De instroomreductie hiervan wordt geraamd op $8 \%$.

De derde stap is dat alleen personen die volgens het huidige richtlijn 'Geen Duurzaam Benutbare Mogelijkheden' hebben in aanmerking komen voor de WAO. Dat leidt tot een extra reductie van $10 \%$. De raming van het effect van de vierde stap wordt niet inhoudelijk geduid door de commissie-Donner. Bij de strengste invulling van 
het nieuwe criterium daalt de WAO-instroom aanvullend nog met $12 \%$ zodat de totale instroomreductie op $67 \%$ wordt geraamd.

De stappen in beide analyses komen sterk overeen. Beide analyses onderscheiden de situatie dat alle gedeeltelijke WAO-uitkeringen worden afgeschaft met uiteraard ongeveer hetzelfde effect op de WAO-instroom. In de analyse voor de EER ontbreekt een benadering voor stap 2 van de commissie-Donner. Het beperken van de WAO-instroom tot alleen de GDBM-gevallen (stap 3 bij Donner) komt inhoudelijk grotendeels overeen met stap 2 waarbij eenieder getroffen wordt bij wie het FIS is geraadpleegd. Ook de geraamde effecten komen sterk overeen: Donner raamt het totaaleffect op $55 \%$ en in de EER wordt het effect voor vrouwen geraamd op $54 \%$ en op 63\% voor mannen. De strengste variant bij Donner (stap 4) komt inhoudelijk sterk overeen met een cumulatie van alle onderscheiden stappen in de EER $(1 \mathrm{t} / \mathrm{m} \mathrm{4})$, waarbij ook een invulling is gegeven voor de termen duurzaam en vermijdbaar. De commissie-Donner raamt het effect op $67 \%$, en in de EER wordt het effect voor vrouwen geraamd op $67 \%$ en op $73 \%$ voor mannen.

Nadere analyses naar enkele achtergrondkenmerken leert dat het effect van de toepassing van de strengste EER-variant het sterkst is voor de WAO'ers van 45 tot 54 jaar. Van de huidige mannelijke WAO'ers van 45 tot 54 jaar zou $76 \%$ geen (gedeeltelijke of volledige) WAO-uitkering meer ontvangen en $71 \%$ van de vrouwelijke WAO'ers van die leeftijd. WAO'ers onder de 25 jaar worden het 'minste' getroffen: $63 \%$ van de mannen en $58 \%$ van de vrouwen zou niet meer in aanmerking komen voor een WAO-uitkering. Helaas is het door het ontbreken van het kenmerk 'diagnose' in één van de analysebestanden niet mogelijk om het effect naar diagnose te berekenen. De verschillen in effecten naar sectoren zijn gering. Deels komt dat doordat informatie alleen op het niveau van uitvoeringsinstelling beschikbaar was in de analysebestanden waarbij gegevens van het SFB ontbraken. De vrouwen bij het GUO worden relatief weinig getroffen $(55 \%)$, de vrouwen bij het USZO het meest (69\%). Bij de mannen zijn het de sectoren GUO en Cadans waar de effecten minder groot zijn $(68 \%)$ en de sectoren Gak en USZO waar de effecten het grootst zijn $(73 \%)$.

\section{Discussie}

Van drie mogelijke maatregelen is onderzocht wat het effect zou zijn geweest op de WAO-instroom in 1999 of 2000 en of de effecten verschillen voor mannen en vrouwen.
Het toepassen van een arbeidsverledeneis van 4 uit 5 zou volgens deze berekening leiden tot een daling van de WAO-instroom van $15 \%$ van de mannen en $18 \%$ van de vrouwen. Het effect is voor vrouwen iets groter dan voor mannen maar mogelijk wordt dit nog gecompenseerd door aanvullend beleid zoals het hanteren van een verzorgingsforfait dat meetelt als arbeidsverleden zoals nu in de WW geschiedt.

Het afschaffen van de lagere ao-klassen treft, ongeacht waar de grens gelegd wordt, meer mannen dan vrouwen. Dat is niet verrassend want uit elk onderzoek en elke statistische publicatie blijkt dat mannen vaker gedeeltelijk arbeidsongeschikt worden dan vrouwen (zie bijvoorbeeld Selten en Copinga ${ }^{6}$ ). Als gedeeltelijke arbeidsongeschiktheid geen recht meer geeft op een WAO-uitkering, zoals in sommige beleidsvarianten wordt voorgesteld, dan zou de WAOinstroom bij mannen dalen met $45 \%$ en bij vrouwen met $33 \%$. Dit is berekend over het jaar 2000. Aangezien het aandeel van gedeeltelijk arbeidsongeschikten in de WAO-instroom is toegenomen van 2000 naar 2002 met 7 procentpunten, ${ }^{7}$ zou het effect voor de huidige WAO-instroom nog groter zijn.

Het beperken van de WAO-instroom tot degenen die duurzaam, vermijdbaar en volledig arbeidsongeschikt zijn, zou kunnen leiden tot een daling met $73 \%$ van de WAO-instroom bij mannen en $67 \%$ bij vrouwen. Tegen de verwachting in is het effect voor vrouwen lager dan voor mannen. Bekend is dat vrouwen vaker om psychische redenen arbeidsongeschikt worden en aangezien in stap $350 \%$ van WAO'ers met een psychische ziekte niet in aanmerking komt voor een WAO-uitkering, was de verwachting dat vrouwen vaker getroffen zouden worden dan mannen. De verklaring hiervoor ligt in de voorafgaande stappen waarin eenieder afvalt die over arbeidscapaciteit beschikt. Het aandeel mannen in de WAO-instroom dat beschikt over arbeidscapaciteit, tot uiting komend in een gedeeltelijke WAO-uitkering of in een FIS-raadpleging, is zoveel groter dan het aandeel vrouwen, dat dit niet meer teniet gedaan wordt door het hogere aandeel psychisch zieken onder vrouwen.

In de strengste variant daalt de totale WAO-instroom met ongeveer $70 \%$. De instroom van volledig arbeidsongeschikten zou dalen met $51 \%$. Dit betekende in 2000 dat ongeveer 32 duizend personen die toen een volledige WAO-uitkering ontvingen dat onder het nieuwe beleid niet meer zouden ontvangen en ongeveer 31 duizend nog wel. Het aantal van 31 duizend ligt nog boven het aantal van 20 duizend dat in een uitgelekte UWV-notitie over het nieuwe WAO-criterium als beoogde bovengrens wordt genoemd. Overigens is dit aantal dichterbij gekomen doordat het aantal nieuwe volledige WAO-uitkeringen in 2001 is gedaald van 63,3 duizend in 2000 tot 58,9 
duizend in 2001. ${ }^{7}$ Vooralsnog is deze daling op zich niet voldoende om na invoering van de strengste variant onder die beoogde bovengrens van 20 duizend nieuwe WAO'ers per jaar te komen. Dit illustreert dat aanvullend op de strengste variant nog ingrijpender maatregelen nodig zouden zijn om een WAO-instroom van 20 duizend personen te realiseren.

Een recent voorgestelde beleidsvariant is om de wachttijd voor de WAO structureel te verlengen van één jaar tot twee jaar. Het effect van deze variant op de WAOinstroom is voor zover bekend niet onderzocht. Het moge duidelijk zijn dat deze verlenging van de wachttijd dient te leiden tot een daling van de WAO-instroom. Donner schatte het aandeel herstelde volledig arbeidsongeschikten op $8 \%$ van de WAO-instroom.

Zoals gezegd is bij de analyses geen rekening gehouden met mogelijke gedragseffecten. Als de ondergrens voor de WAO naar $35 \%$ gaat en werkende gedeeltelijk arbeidsongeschikten recht hebben op een zogeheten loonaanvulling, hebben zowel werkgevers als werknemers er belang bij dat een werknemer die arbeidsongeschikt is boven die grens komt. Het belang voor de werkgever kan op gespannen voet komen te staan met dat van de werknemer als de werkgever verantwoordelijk is voor de betaling van de zogeheten loonaanvulling. Indien er nog sprake is van volledige ongeschiktheid tot het verrichten van arbeid hebben beiden er belang bij de arbeidsongeschiktheid te benadrukken in plaats van de arbeidsmogelijkheden. De beoordeling van de verzekeringsarts en de arbeidsdeskundige resulteert namelijk of in een arbeidslevenslange loongerelateerde WAO-uitkering, of in een duikvlucht via de WW richting sociaal minimum (IOAW) en/of financiële afhankelijkheid van de partner.

De indruk bestaat dat de eerste twee onderzochte maatregelen, arbeidsverledeneis en afschaffing lagere ao-klassen voor de praktijk uitvoerbaar zijn. Of het beleidsmatig ook uitvoerbaar is, staat, gezien de commotie over het onverzekerd raken van beroepsrisico's en de wens om dus onderscheid te maken tussen risque social en risque professional, nog niet vast. De uitvoerbaarheid van de derde maatregel die we hebben onderzocht, staat nog niet vast. In de uitgelekte notitie van het UWV wordt bijvoorbeeld voorgesteld om het aantal te duiden functies in het CBBS tot minimaal één te beperken in plaats van het huidige aantal van drie. Overigens is dit een beduidend mildere invulling dan die in dit artikel is gepresenteerd. Onbekend is nog welke criteria de uitvoerders aangereikt krijgen om vast te stellen of de arbeidsongeschiktheid 'volledig, duurzaam en niet vermijdbaar' is, aannemende dat de omschrijving van Donner gevolgd gaat worden. Het moge bekend zijn dat de duur van arbeidsongeschiktheid slecht voorspelbaar is doordat het een combinatie is van meerdere factoren die de arbeidsongeschiktheid bepalen. Daarvan is de medische oorzaak wel de 'conditio sine qua non' maar niet de enige factor.

Donner constateerde in zijn analyse dat het aanscherpen van de WAO-criteria en bewaking van de instroom in de WAO in de praktijk wel effect hebben, maar geen afdoende oplossing vormen voor het WAO-probleem. Problemen ontstaan namelijk in de periode van ziekteverzuim die vooraf gaat aan instroom in de WAO. De beleidsvoornemens vormen het zoveelste voorbeeld van het zoeken van een oplossing in het benoemen van vergaande nieuwe beleidsvoorstellen in plaats van het verbeteren en bijsturen van de uitvoeringspraktijk. De Algemene Rekenkamer heeft in een recent rapport 'Tussen beleid en uitvoering: lessen uit recent onderzoek van de Algemene Rekenkamer' gewezen op de overdaad aan ingrijpende beleidsvoornemens en een slechte aansluiting tussen beleidsambities en de uitvoeringspraktijk waar het probleem ligt. En recent heeft Barentsen8 aandacht gevraagd voor verbetering van de uitvoeringspraktijk in plaats van de wetgeving. Niet de wetgeving als zodanig maar de uitvoering van de WAO vormt de achilleshiel van de sociale zekerheid.

De dalende WAO-instroom suggereert dat beleid en uitvoering effectiever worden en de urgentie voor ingrijpende maatregelen afneemt. ${ }^{1}$

\section{Literatuur}

Adviescommissie Arbeidsongeschiktheid. Werk maken van arbeidsgeschiktheid. Rapport van de commissie-Donner. Doetinchem: Elsevier, 2001.

Besseling JJM, Olde C de. Emancipatie-effectrapportage commissie-Donner. Den Haag: Werkdocument ministerie van SZW, september 2002.

CPB. De effecten van een aantal WAO-voorstellen d.d. 7 juni 2000, kamerstukken $22187 \mathrm{nr} .107$ herdruk.

Jacobi AM, Muller B, Besseling JJM, Kerk TJ aan de. Effecten aanscherping toetredingseisen ww per 1 maart 1995. Den Haag: VUGA, 1996.

CPB. De effecten van 3 WAO-maatregelen d.d. 3 maart 1999. Kamerstukken 22187, nr 107 herdruk

Selten R., Coppinga M. Wie komen in de WAO? Voorburg: CBS, 13 december 2002.

Bron: UWV, Kroniek van de sociale verzekeringen 2002. Amsterdam: UWV, 2003.

Barentsen B. Arbeidsongeschiktheid, aansprakelijkheid, bescherming en compensatie. Deventer: Boom Juridische uitgevers, Kluwer, 2003.

\footnotetext{
${ }^{1}$ Overigens zal nog moeten blijken welk deel van de sterke daling in de WAO-instroom blijvend is. Door de Wet verbetering poortwachter is de WAO-beoordeling bij een deel van de langdurig zieken uitgesteld op verzoek van de werkgever of omdat UWV de reïntegratie-inspanningen als onvoldoende heeft beoordeeld.
} 